\title{
THE 650 KM MANTLE DISCONTINUITY
}

Don L. Anderson

Seismological Laboratory

California Institute of Technology, Pasadena, Californta 91125

Abstract. The bulk moduli of silicate and oxide solid solutions depend very little on iron content, but are diagnostic of crystal structure. Comparison of laboratory with seismic data suggests that the upper mantle mineral assemblages as a function of depth are: I. olivine + pyroxene + garnet $(200-400 \mathrm{~km})$, II. $\beta$-spinel + pyroxenegarnet solid solution $(400-500 \mathrm{~km})$, III. $(\beta+\gamma)-$ spinel + pyx-ga s.s. (500-600) km, IV. $\gamma$-spinel + $\mathrm{SiO}_{2}$ (stishovite) or mixed oxides $(650-800 \mathrm{~km}$ ) and $\nabla$. mixed oxides or perovskite $+\mathrm{MgO}(>800 \mathrm{~km})$. The $650 \mathrm{~km}$ discontinuity is primarily due to phase changes in the pyroxene-garnet, rather than the olivine, portion of the mantle.

Birch (1961) discovered an empirical relationship between sound velocity, density and mean atomic weight which has since been applied widely. Iron content increases the mean atomic weight, Increases the density and decreases the compressional and shear velocity. A theoretical basis for these relations was given by Anderson (1967a). An examination of published uitrasonic, static compression and shock wave data(Anderson, in preparation) shows that the bulk modulus is almost independent of iron content More specifically, as $\mathrm{Fe}$ substitutes for $\mathrm{Mg}^{\mathrm{f}}$ in systems such as pyroxenes, olivines and garnets, the density increases but the bulk modulus either decreases only slightly or, in some cases, increases. Fits to the available data are shown in Fig. 1. The pyroxene, olivine and garnet lines are well constrained. The (Mg, $\mathrm{Fe}) 0$ line joins measurements for the end members. The B-spinel line is tentative; it joins the preferred value for $\beta-\mathrm{Mg}_{2} \mathrm{S1O}_{4}$ (Mizukami et al. 1975), which has a large uncertainty with $\beta-\mathrm{Mn}_{2} \mathrm{GeO}_{4}$ (Liebermann, 1975). This procedure is felt Justified since $\alpha-\mathrm{Mn}_{2} \mathrm{GeO}_{4}$ behaves as a silicate, falling on the olivine line, and the resulting $\beta$-spinel line is subparalle1 to most of the other systems. In addition to the silicate systems there is also data for $\mathrm{Mg}_{2} \mathrm{GeO}_{4}-\mathrm{Fe}_{2} \mathrm{GeO}_{4}$ (sp) and $\mathrm{MgAl}_{2} \mathrm{O}_{4}^{-}$ $\mathrm{FeAl}_{0} 0$ (sp). In these two cases the buIk ${ }^{4}$ modulus increases slightly with iron content. The olivine and pyroxene mixed oxides lines are computed from the properties of $\mathrm{MgO}, \mathrm{FeO}$, and $\mathrm{SIO}_{2}$ (stishovite). The observed trends are consistent with the KV constant rule of Anderson and Anderson (1970). The perovskite, (Mg, $\mathrm{Fe}) \mathrm{SiO}_{3}$, region is the most uncertain. It is inferred from the systematics of Davies (1974) and Liebermann (1975).

The fact that the bulk modulus is independent of density, or Iron content, in an isostructural

Copyright 1976 by the American Geophysical Union. series means this parameter cannot be used to infer composition of the mantle. However, the bulk modulus is a good diagnostic of crystal structure and increases in the order pyroxene, $\alpha$-olivine, $\beta$-spinel, garnet, $\gamma$-spinel, pyroxene oxides and perovskite (inferred). Except for the uncertainty in the location of the B-spinel line the only phases that cannot be distinguished unambiguously on the basis of bulk modulus are $\gamma$-spinel and mixed oxides in olivine proportions $(\delta)$.

It is usually assumed that the $650 \mathrm{~km}$ seismic discontinuity in the mantle is due to a phase change in the predominantly olivine component of the mantle. Specifically, it has been attributed to the collapse or disproportionation of spinel to a post-spinel structure having the properties of the mixed oxides (Anderson, 1967b). Th1s postspinel phase could be the simple oxides, $\mathrm{Sr}_{2} \mathrm{PbO}_{4}$ structure or perovskite plus periclase, al1 of 4 which have similar densities. Anderson (1969) and Davies (1974), however, showed that the elastic moduli of spinels and mixed oxides are similar. The sharpness of the discontinuity (Whitcomb and Anderson, 1970; Richards, 1972) is also difficult to explain with transformations in the olivine component (Anderson, 1967b). All of this suggests that the large seismic discontinuity at 650

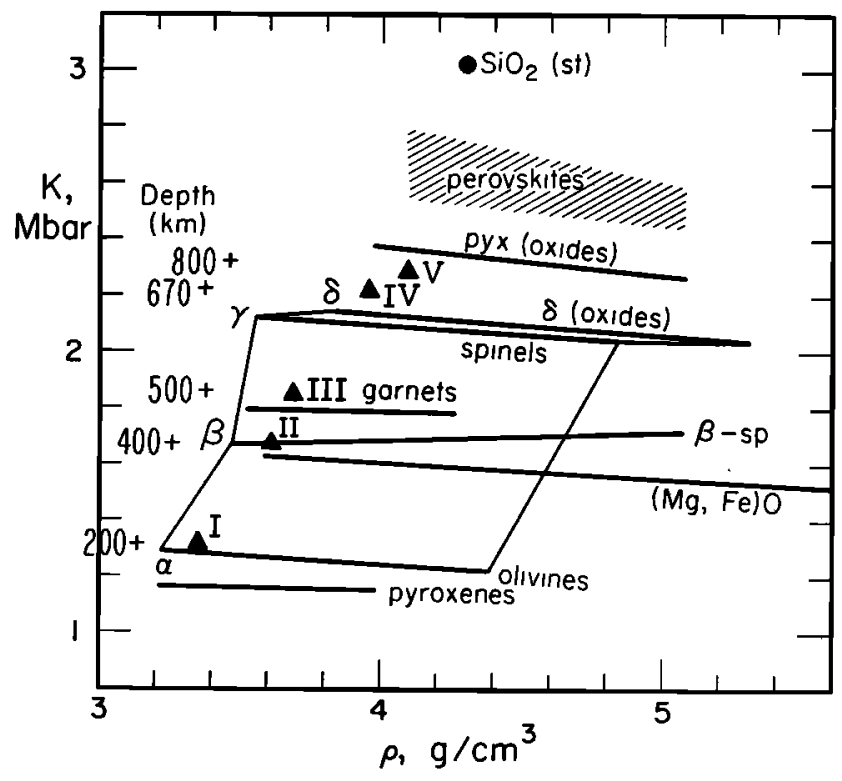

Figure 1. Bulk modulus, $k$, versus density, $\rho$, for various crystal structures. The solid triangles are extrapolated from various regions of the mantle. 
$\mathrm{km}$ may be unrelated to transformations in olivine. The spinel-oxides disproportionation involves a large density increase but, because of the increase in coordination, the average siliconoxygen distance increases. This lessens the repulsive forces between ions. Thus, a smaller increase, or even a decrease, in bulk modulus is expected than for phase changes which do not involve a change in coordination. This point has also been made by Liebermann and Ringwood (1973). A decrease in bulk sound velocity would be expected for the spinel-oxides phase change. Actually, the $650 \mathrm{~km}$ discontinuity represents a large increase in bulk modulus and seismic velocities.

The $K-\rho$ trajectory of successive phase changes is $\mathrm{Mg}_{2} \mathrm{SiO}_{4}$ (forsterite) is shown in Figure 1 . These are $\alpha$ (olivine), $\beta$ ( $\beta$-spine1), $\gamma$ ( $\gamma$-spinel) and $\delta$ (mixed oxides) Also shown is the $\mathrm{Fe}_{2} \mathrm{SHO}_{4}$ (fayalite) $\alpha-\gamma$ trajectory. An estimate (L1ebermann, 1974) of the bulk modulus of 11menite, a possible high pressure form of pyroxene and garnet, is close to the spinel line although displaced to higher density.

The conclusion is that bulk modulus depends primarily on crygtal structure and only slightly affected when $\mathrm{Fe}$ substitutes for $\mathrm{Mg}^{2+}$. In addition, the bulk moduli of silicate spinels and the mixed oxides, are virtually identical and there should be only a slight bulk modulus change associated with this disproportionation. This is contrary to the observations of the $650 \mathrm{~km} \mathrm{dis-}$ continuity.

The results of a preliminary attempt to extrapolate the properties of the varlous regions of the mantle to 1 bar and $20^{\circ} \mathrm{C}$ are indicated by triangles. Finite strain equations of state (Sammis et a1., 1970) are fitted to the presumably homogeneous reglons between discontinuities and solved for $k$ and $\rho$. The procedure is identical to that used By Burdick and Anderson (1975) and the Earth model used 1s C2 (Anderson and Hart, 1976). Uncertainties in this procedure will be discussed in a forthcoming paper (Butler and Anderson, in preparation). The regions fitted, as indicated by the depth scale at the left of the figure are I $(200-400 \mathrm{~km})$, II $(400-500 \mathrm{~km})$, III $(500-670 \mathrm{~km})$, IV $(670-800 \mathrm{~km})$ and $V$ (lower mantle).

The upper mantle $(300-400 \mathrm{~km})$, the lowermost solid triangle (I), is close to the olivine line and between the pyroxene and garnet lines. A predominantly olivine and pyroxene mantle with subordinate garnet is indicated. Olivine, with pyroxene and garnet in the proportions $7: 2$, satisfies the bulk modulus. Region II, 400-500 $\mathrm{km}$, falls on the $\beta$-spinel 1ine. It can also be satisfied by olivine-pyroxene-garnet mantle with more garnet than region $I$. The composition of the mantle can be uniform across the $400 \mathrm{~km}$ discontinuity if a large fraction of the pyroxene component has entered the garnet structure as proposed by Ringwood (1967). We interpret this region of the mantle as being composed of olivine in the $\beta$-phase, pyroxene and pyroxene-garnet solid solution in the garnet structure. Region III, between 500 and $650 \mathrm{~km}$, is distinctly below the bulk modulus inferred for the $\gamma$-spinel phase of olivine and lies close to the inferred $k$ for garnet. If all of the pyroxene component of the mantle has entered the garnet structure it is probable that the olivine component of the mantle is in the mixed $\beta-\gamma$ phase region. The uncertainty in the $K$ of $\beta$-spinel is such that this region could be entirely $\beta$-spinel and garnet. The assemblage $\gamma$-spinel plus stishovite seems to be ruled out.

Both the density and bulk modulus of the mantle immediately below $670 \mathrm{~km}$, region IV, are consistent with either a mixed oxide assemblage or $\gamma$-spinel plus stishovite but not with ilmenite plus Mg0. Regton $V$ could be the same assemblage with more $\mathrm{SHO}_{2}$ (stishovite), 1.e. closer to the pyroxene stoichiometry, or the perovskite plus Mg0, as suggested by recent high pressure results (Liu, 1975).

We propose that it is the pyroxene-garnet component of the mantle, transforming from the garnet structure to the mixed oxides or perovskite structure that is mainly responsible for the 650 $\mathrm{km}$ discontinulty. The deeper mantle, below about $850 \mathrm{~km}$, is consistent with an oxide mixture or perovskite plus $\mathrm{MgO}$.

This interpretation reconciles several pieces of seismic data. The $650 \mathrm{~km}$ region seems to be both spread out (Helmberger and W1ggins, 1971; Helmberger and Engen, 1974) and sharp (Engdah1 and Flinn, 1969; Whitcomb and Anderson, 1970). The former characteristic is required to satisfy the amplitudes of refracted waves; the latter characteristic is required to satisfy the amplitudes of short perfod reflected waves. Both characteristics can be satisfied if the olivine above the discontinuity is in its mixed phase region with the $\beta-\gamma$ transition going further to the right with depth. The velocity jump at 650 is primarily due to the pyroxene-garnet to mixed oxides reaction. It remains to be seen whether the latter can be sharp. It will be if the magnesium and Iron rich end members transform at similar pressures.

The major constituents of the upper mantle are olivine, pyroxene and garnet. Ringwood (1967) showed that at high pressures, enstatite is capable of dissolving in the garnet structure with a $10 \%$ increase in density in the $\mathrm{MgSIO}_{3}$ component. The solubility at $1000^{\circ} \mathrm{C}$ increases rapidiy at about 100 kbars $(300 \mathrm{~km})$ and is essentially complete by about 150 kbars $(450 \mathrm{~km})$. The effect of temperature is not known but if it is small we expect that most of the pyroxene component of the mantle has entered the garnet structure below the $400 \mathrm{~km}$ discontinuity.

The thermodynamic data required to calculate the reaction boundary between this complex garnet and mixed oxides is not available. Data for the almandine-pyrope system itself is sparse. Using selected estimates of Ahrens (1972, 1973), Anderson (1967b) and Ahrens and Syono (1967) and assuming that the mantle pyroxene-garnet solid solution behaves as almandine-pyrope garnet, the calculated transition pressures for the end members differ by only 4 kilobars compared with the difference of $100 \mathrm{~kb}$ and $120 \mathrm{~kb}$ found, respectively, for the end members in the olivine-spinel and spinel-post spinel transitions. These latter phase changes will be spread out over a considerable depth interval but the phase loop of the 
garnet-oxides reaction has almost collapsed to a line, a requirement for a sharp transition. Taken at face value the garnet-oxides transition is less than $12 \mathrm{~km}$ thick. This is a highly tentative conclusion based on inadequate data and questionable assumptions but it suggests that the garnet-oxides boundary may be sharp. The depth is about $690 \mathrm{~km}$ thick at room temperature. If the garnet-oxides, or garnet-perovskite, transformation occur in the mantle it would be by far the largest, and possibly, the sharpest discontinuity. It would follow that the $\Delta S$ of reaction is near zero. Although a subducting slab could penetrate the $670 \mathrm{~km}$ discontinuity it would not have the negative buoyancy associated with the $400 \mathrm{~km}$ discontinuity and would therefore be effectively braked at this level.

Acknowledgments. I would like to acknowledge discussions with Robert Llebermann, and A. E. Ringwood. Rhett Butler did some of the calculations. Tom Ahrens commented on the manuscript. The manuscript was considerably improved by the comments of a conscientious anonymous reviewer. This research was supported by a grant from the Standard 011 Company of California.

Contribution No. 2716, Division of Geological and Planetary Sciences, California Institute of Technology, Pasadena, Callfornia 91125.

\section{References}

Ahrens, T. J., The mineralogical distribution of Iron in the upper mantle, Phys. Earth Planet. Interiors, 5, 267-281, 1972.4

Ahrens, T. J., Petrological properties of the upper $670 \mathrm{~km}$ of the Earth's mantle: Geophysical Implications, Phys. Earth Planet. Interiors, 7, 167-186, 1973 .

Ahrens, T. J., and Y. Syono, Calculated mineral reactions in the Earth's mantle, J. Geophys. Res., 72, 4181-4188, 1967.

Anderson, Don L., A seismic equation of state, Geophys. J. Roy. Astr. Soc., 13, 9, 1967a.

Anderson, D. L., Phase changes in the upper mantle, Science, 157, 1165-1173, 1970.

Anderson, D. L., Bulk modulus-density systematics: J. Geophys. Res., 75, 3857-3864, 1969.

Anderson, D. L., and 0. L. Anderson, The bulk modulus-volume relationship for oxides, J. Geophys. Res., 75, 3493-3500, 1970.

Anderson, D. L., and R. Hart, An earth model based on free oscillations and body waves, J. Geophys. Res., in press, 1976.

Birch, F., The velocity of compressional waves in rocks to 10 kilobars, 2, J. Geophys. Res., 66, $2199,1961$.

Burdick, L. J., and D. L. Anderson, Interpretation of velocity profiles of the mantle, J. Geophys. Res., 80, 1070-1074, 1975.

Davies, G. F., Elasticity crystal structures and phase transitions, Earth Planet. Sci. Letters, 122, 339, 1974.

Engdah1, E. R., and E. A. Flinn, Seismic waves reflected from discontinuities within the upper mantle, Science, 163, 177, 1969.

Helmberger, D. V., and R. A. Wiggins, Upper mantle structure of midwestern United States, J. Geophys. Res., 76, 3229-3244, 1971.

Helmberger, D. V., and G. Engen, Upper mantle shear structure, J. Geophys. Res., 79, 4017-4028, 1974.

Liebermann, R., Elasticity of pyroxene-garnet and pyroxene-1lmenite phase transformations in germanates, Phys. Earth P1anet. Int., $\underline{8}$, 361-374, 1974.

Liebermann, R., Elasticity of olivine, beta ( $\beta$ ) and spinel $(\gamma)$ polymorphs of germanates and siltcates, Geophys. J. R. Astr. Soc., 42, 899-930, 1975.

Liebermann, R. and A. E. Ringwood, Birch's law and polymorphic phase transformations, J. Geophys. Res., 78, 6926, 1973.

Liu, L., Post-oxide phase of olivine and pyroxene and mineralogy of the mantle, Nature, 25, $510,1975$.

Mizukami, S., A. Ohtani and N. Kawai, High pressure $X$-ray diffraction studies on $\beta$ and $\gamma-\mathrm{Mg} \mathrm{S10}$, Phys. Earth Planet. Interiors, $10,177-182,1975$

Richards, P. G., Seismic waves reflected from velocity gradient anomalles within the earth's upper mantle, Zeitschrift fur Geophysik, 38, 517, 1972.

Ringwood, A. E., The pyroxene-garnet transformation in the earth's mantle, Earth Planet. Sc1. Letters, 2, 255-263, 1967.

Sammis, C. G., D. L. Anderson and T. H. Jordan, Application of isotropic finite strain theory to ultrasonic seismological data: J. Geophys. Res., 75, 4478-4480, 1970.

Whitcomb, J. H., and D. L. Anderson, Reflection of $P^{\prime} P^{\prime}$ seismic waves from discontinuities in the mantle, J. Geophys. Res., 75 , 5713-5728, 1970.

(Received February 27, 1976 . revised April 14, 1976; accepted Apri1 30, 1976.) 